\author{
JORGE J. GUMUCIO, EDITOR \\ Department of Internal Medicine \\ Division of Gastroenterology (111D) \\ VA Medical Center/University of Michigan \\ Ann Arbor, Michigan 48105
}

\section{THE INFLUENCE OF PROPANOLOL ON PORTOSYSTEMIC SHUNTING}

Sarin SK, Groszmann RJ, Mosca PG, Rojkind M, Stadecker MJ, Bhatnagar $R$, Reuben $A$, et al. Propranolol ameliorates the development of portal-systemic shunting in a chronic murine schistosomiasis model of portal hypertension. J Clin Invest 1991;87:1032-1036.

\section{ABSTRACT}

We investigated the role of early portal hypotensive pharmacotherapy in preventing the development of portal-systemic shunting in a portal hypertensive model of chronic murine schistosomiasis induced by infecting C3H mice with 60 cercariae of Schistosoma mansoni. Propranolol was administered in drinking water to 20 animals for a period of 6 wk at a dose of 10 $\mathbf{m g} \cdot \mathbf{k g}^{-1} \mathbf{d}^{-1}$, starting at 5 wk of schistosomal infection. 32 age-matched mice with chronic schistosomal infection served as controls. All animals were studied 11 wk after the infection. Compared with controls the portal pressure $(10.8 \pm 0.40 \mathrm{~mm} \mathrm{Hg})$ was significantly lower $(P<\mathbf{0 . 0 0 1})$ in the propranololtreated animals $(7.9 \pm 0.80 \mathrm{~mm} \mathrm{Hg})$. Portal-systemic shunting was decreased by $79 \%$, from $12.2 \pm 3.34 \%$ in controls to $2.5 \pm 0.99 \%$ in the propranolol group $(P<0.05)$. Portal venous inflow was reduced by $38 \%$ in the propranolol treated animals $(2.50 \pm 0.73 \mathrm{ml} / \mathrm{min}$; $n=6)$ compared with controls $(4.00 \pm 0.34 \mathrm{ml} / \mathrm{min}$; $n=8 ; P<0.05$ ). The worm burden, the granulomatous reaction, the collagen content of the liver, and the serum bile acid levels were not significantly different between the two groups of animals. These results demonstrate that in chronic liver disease induced by schistosomiasis, the development of portal-systemic shunting can be decreased or prevented by the reduction of flow and pressure in the portal system.

\section{COMMENTS}

Schistosomiasis is the most common cause of chronic liver disease in the world, and its major complications are portal hypertension and bleeding esophageal varices caused by portosystemic shunting. One of the main objectives of this elegant study by Sarin et al. was to investigate whether a reduction in portal flow and pressure induced by propranolol at an early stage in the disease process could influence the development of portosystemic shunting (PSS). The answer from this study was positive, and the earlier the therapy began, the greater the reduction associated with this therapy (e.g., 5 wk after schistosomal infection was initiated [79\%] vs. 7 wk [57\%]). In the propranolol-treated group

$\mathbf{3 1 / 8 / 3 3 1 0 8}$ a significant reduction was seen in portal pressure $(27 \%)$ and in portal venous inflow (38\%). No correlation was seen between either the fall in portal pressure or in portal venous inflow and the effect on PSS, leaving the authors to surmise that the combination of the two might explain the effect on PSS.

The original concept of propranolol therapy was that a combination of a reduction in cardiac output and local splanchnic blood flow by $\beta$-blockade would result in a reduction in portal pressure (1). Cardiac output was not measured in this study, so was it reduced? The combination of a drop in heart rate and in mean arterial pressure (to a much greater extent than that seen in patients) suggests it was, but the fact that hepatic arterial flow was not decreased in the treated group makes one wonder. Furthermore, the mean heart rate decreased from 554 to 493 beats/min in the treated group, a fall of only $11 \%$. This is surprising because the high basal heart rate would suggest that this is a major factor in maintaining cardiac outflow. The decrease compares with a fall of $30 \%$ in rats with portal vein stenosis (2) and a recommended decrease of $25 \%$ to produce a significant fall in portal pressure and portal venous inflow in patients (3). Again, these much greater decreases in cardiac output were not accompanied by comparable decreases in systemic blood pressure in patients $(7 \%)$ (4) compared with nearly $15 \%$ in this animal model.

The group from Yale have pioneered the concept from their previous animal models $(5,6)$ that portal venous inflow is increased in cirrhosis. However, they do not indicate that this is the case in this model. In fact, although portal hypertension precedes PSS by approximately $2 \mathrm{wk}$, we do not know whether this is associated with increased portal venous inflow. Indeed, portal venous inflow may be decreased in animal models of schistosomiasis (7).

Nevertheless, propranolol does cause a decrease in portal venous inflow in this model. Therefore what is the mechanism of the propranolol effect on PSS? The temporal studies would indicate an indirect effect by way of the prevention of portal hypertension. The lack of correlation between PSS and the reduction in portal pressure and portal venous inflow may be because both factors are important and additive. It may also mean that an additional factor exists. This factor might be a direct vasoconstrictive ( $\beta_{2}$-adrenergic blockade) on the shunts themselves. For example, a single oral dose of propranolol can cause a decrease in indocyanine green clearance, the decrease in clearance being caused by a decrease in hepatic extraction of indocyanine green, which in turn can be caused by a decreased shunting. 
Finally, what is the clinical significance of this finding? Patients with schistosomiasis tend to come from the rural areas of developing countries. If patients at risk of bleeding can be found, started on propranolol and have the bleeding controlled at least in terms of their heart rate, this would constitute an advance. However, with limited medical resources, it will be an extremely difficult undertaking.

Laurence M. Blendis, M.D.

Toronto General Hospital

University of Toronto

9 Eaton $N-223$

Toronto, Ontario

Canada M5G1L7

\section{REFERENCES}

1. Lebrec D, Poignard T, Hillon P, Benhamou JP. Propranolol for prevention of recurrent gastrointestinal bleeding in patients with cirrhosis: a controlled study. N Engl J Med 1981;305:1371-1374.

2. Hillon P, Blanchet L, Lebrec D. Effect of propranolol on hepatic blood flow in normal and portal hypertensive rats. Clin Sci 1982;63:29-32.

3. Lebrec D, Hillon P, Muroz C. The effect of propranolol on portal hypertension in patients with cirrhosis: a hemodynamic study. HEPATOLOGY 1982;2:523-527.

4. Burroughs AK, Jenkins WJ, Sherlock S. Controlled trial of propranolol for the prevention of recurrent variceal hemorrhage in patients with cirrhosis. New Engl J Med 1983;309:1539-1542.

5. Sikuler E, Kravetz D, Groszmann RJ. Evolution of portal hypertension and mechanisms involved in its maintenance in a rat model. Am J Physiol 1985;248:G618-G625

6. Vorobioff J, Bredfeldt JE, Groszmann RJ. Increased blood flow through the portal system in cirrhotic rats. Gastroenterology 1984;87:1120-1126.

7. Morgan JS, Groszmann RJ, Rojkind M, Enriquez R. Hemodynamic mechanisms of emerging portal hypertension caused by schistosomiasis in the hamster. HEPATOLOGY 1990;11:98-104.

\section{LOSS OF HBsAg AFTER INTERFERON- $\alpha$ TREATMENT: CURE OF CHRONIC HEPATITIS B VIRUS?}

Korenman $J$, Baker B, Waggoner $J$, Everhart JE, DiBisceglie AM, Hoofnagle JH. Long-term remission of chronic hepatitis B after alpha-interferon therapy. Ann Intern Med 1991;114:629-634.

\section{EDITOR'S ABSTRACT}

Sixty-four patients with chronic hepatitis B who were treated with interferon- $\alpha$ (recombinant IFN- $\alpha-2 a$ in 9 patients, recombinant IFN- $\alpha-2 b$ in 50 patients and lymphoblastoid IFN- $\alpha-n 1$ in 5 patients) in protocols conducted at the Liver Diseases Section of the National Institutes of Health between 1984 and 1986 were observed with sequential determinations of serum ALT levels, HBsAg and serological markers of hepatitis B virus replication (HBeAg, hepatitis B virus DNA polymerase, hepatitis B virus DNA by blot hybridization and hepatitis B virus DNA by polymerase chain reaction). Among the 64 treated patients, 23 responded to interferon treatment with loss of $\mathrm{HBeAg}$ and improvement in serum ALT. Three patients $(13 \%)$ re- lapsed, all within the first year of follow-up. The remaining 20 patients continued to have no detectable HBeAg or hepatitis B virus DNA (dot blot) in serum during follow-up of 3 to $7 \mathrm{yr}$ (mean $=4.3 \mathrm{yr}$ ), although 3 patients had minimal elevations of serum ALT. Thirteen patients (65\%) lost HBsAg between 0.2 and 6 yr (mean $=3 \mathrm{yr}$ ) after loss of HBeAg. Although none of the 20 patients had detectable serum hepatitis B virus DNA (dot blot), all 7 patients with persistent HBsAg had detectable serum hepatitis B virus DNA by the polymerase chain reaction. Sequential testing in HBsAg - patients indicated the serum hepatitis B virus DNA usually became undetectable by the polymerase chain reaction at about the time of loss of HBsAg. Only 2 of $13 \mathrm{HBsAg}$ - patients had hepatitis B virus DNA detectable in serum by the polymerase chain reaction.

\section{COMMENTS}

Chronic hepatitis B is a common and usually persistent infection. The infection has classically been divided into two phases, the early replicative phase and the later nonreplicative phase $(1,2)$. Progressive liver injury occurs during the phase of $\mathrm{HBV}$ infection when active viral replication occurs. This phase is characterized by the presence of $\mathrm{HBeAg}$ and detectable HBV DNA in serum by dot blot or soluble hybridization assays (3). Cirrhosis evolves at an annual incidence of nearly $6 \%$ of patients regardless of the histological severity (4). However, in those with severe $\mathrm{CAH}$, cirrhosis develops in nearly all patients within $5 \mathrm{yr}$, and survival is diminished $(4,5)$. Spontaneous seroconversion from $\mathrm{HBeAg}$ to anti-HBe + occurs at an annual rate of approximately $5 \%$ to $15 \%$ (1). This postseroconversion phase of infection is typically characterized by normalization of liver tests, histological improvement and loss of symptoms (6). Although this latter phase has been termed the nonreplicative phase of infection because of the loss of tissue HBcAg and serum HBV DNA by dot blot or soluble hybridization, the article by Korenman and colleagues demonstrates that serum HBV DNA persists by the more sensitive technique of polymerase chain reaction (7). Thus the previous term nonreplicative should be replaced by the more accurate label low replicative or latent phase (8). Although $\mathrm{HBeAg}$ to anti-HBe seroconversion is common, clearance of infection with loss of HBsAg (and serum HBV DNA by the polymerase chain reaction) has been reported to be unusual, with an annual rate of $1 \%$ to $2 \%(9,10)$. It has been assumed that the persistence of serum HBsAg after clearance of other markers of HBV infection reflected integration of portions of viral genome. The report of Korenman et al. suggests that HBV DNA is actually eradicated when HBsAg is lost (7). However, it remains to be shown whether a truly nonreplicative phase of infection exists or whether occult HBV sequences remain in the liver or in extrahepatic sites such as peripheral blood mononuclear cells (11).

The main goal of antiviral and immunomodulatory therapies in patients with chronic hepatitis B has been the clearance of markers of the replicative phase of infection (HBeAg and serum HBV DNA polymerase or 